Article

\title{
New Polyprenylated Phloroglucinol and Other Compounds Isolated from the Fruits of Clusia nemorosa (Clusiaceae)
}

\author{
Rafaela Oliveira Ferreira ${ }^{1, *}$, Tania Maria Sarmento da Silva ${ }^{2}$ and Mário Geraldo de Carvalho ${ }^{1}$ \\ 1 Departamento de Química, Universidade Federal Rural do Rio de Janeiro, 23890-000 Seropédica, \\ Brazil; E-Mail: mgeraldo@ufrrj.br \\ 2 Departamento de Ciências Moleculares, Universidade Federal Rural de Pernambuco, \\ 52171-900 Recife, Brazil; E-Mail: sarmentosilva@gmail.com \\ * Author to whom correspondence should be addressed; E-Mail: rafaellaoliveira@ufrrj.br; \\ Tel.: +55-21-972-818-363; Fax: +55-21-2682-1120.
}

Academic Editor: Derek J. McPhee

Received: 21 May 2015 / Accepted: 22 July 2015 / Published: 6 August 2015

\begin{abstract}
Clusia nemorosa has been widely used in folk medicine to treat various ailments, including headaches and inflammation. Investigation of the fruits of Clusia nemorosa (Clusiaceae) led to the isolation and characterization of a new phloroglucinol derivative, named 6S,8S,28S-nemorosic acid (1), together with seven known compounds: friedelin (2), $\beta$-sitosterol (3), stigmasterol (4), $\beta$-sitosterol glycoside (5), kaempferol (6), quercetin (7) and dimethyl citrate (8). The structures were determined by extensive 1D- and 2D-NMR, CD and MS spectroscopic analyses.
\end{abstract}

Keywords: Clusiaceae; Clusia nemorosa; phloroglucinol; nemorosic acid; flavonoid; triterpenoid

\section{Introduction}

The Clusiaceae family, also known Guttiferae, is characterized by the presence of flower resin and latex in most of its species [1]. The genus Clusia presents a notable metabolite diversity, including benzophenones, xanthones and biflavonoids [2-5]. Several species are used in folk medicine all around the world to treat rheumatism, stomach problems and as a purgative [6]. Phytochemical and pharmacological studies of plants belonging to this genus have reported many biological activities, such as antibacterial, antioxidant, antitumour, antimicrobial and anti-inflammatory properties [7]. (-)-Nemorosonol, a prenylated 
benzophenone, exhibited antimicrobial activity against Escherichia coli, Staphylococcus aureus, Bacillus subtilis, Micrococcus luteus, Aspergillus niger, Trichophyton mentagrophytes and Candida albicans [8]. The biflavonoids GB1-7"O-glucoside and GB1a-7"O-glucoside showed promising free radical scavenging capacity in in vitro assays [5]. Phloroglucinol derivatives exhibited chemopreventive properties and inhibited NO production [9]. The Clusia genus thus represents an important source of bioactive compounds.

Clusia nemorosa Mey., popularly known as "pororoca", is a tree that is widespread in the northeast region of Brazil [10]. This species has been widely used in folk medicine to treat headaches and inflammation [11]. Prior phytochemical studies of the fruits of this species led to the isolation of a polyisoprenylated benzophenone and phloroglucinol derivatives $[12,13]$. The additional study of this species presented herein allowed us to identify a new phloroglucinol derivative, named nemorosic acid (1), as well as seven known compounds that were identified for the first time in the fruits: friedelin (2), $\beta$-sitosterol (3), stigmasterol (4), $\beta$-sitosterol glycoside (5), kaempferol (6), quercetin (7) and dimethyl citrate (8).

\section{Results and Discussion}

The fruit of Clusia nemorosa was extracted with dichloromethane $\left(\mathrm{CH}_{2} \mathrm{Cl}_{2}\right)$ and methanol $(\mathrm{MeOH})$. The fractionation of these extracts and the analysis of the fractions allowed us to obtain seven known compounds - friedelin [14], $\beta$-sitosterol [15], stigmasterol [15], $\beta$-sitosterol glycoside [16], kaempferol [17], quercetin [17] and dimethyl citrate [18] —as well as a new phloroglucinol derivative, named nemorosic $\operatorname{acid}(\mathbf{1})$.

Nemorosic acid (1) was isolated as an optically active $\left([\alpha \mathrm{D}]=-5.34^{\circ}\right)$ yellow gum. The molecular formula was established as $\mathrm{C}_{31} \mathrm{H}_{44} \mathrm{O}_{7}$ on the basis of negative ESI-MS data (found $m / z$ 527.3220, $[\mathrm{M}-\mathrm{H}]^{-}$, calc. 527.3009). The IR spectrum displayed absorptions of hydroxyl $\left(3435 \mathrm{~cm}^{-1}\right)$ and carbonyl groups $\left(1707 \mathrm{~cm}^{-1}\right)$, as well as other signals. The ${ }^{1} \mathrm{H}$ - and ${ }^{13} \mathrm{C}-\mathrm{NMR}$ data (Table 1$)$ suggested that $\mathbf{1}$ was a phloroglucinol derivative. The structure was defined by the detailed analysis of $2 \mathrm{D}-\mathrm{NMR}\left({ }^{1} \mathrm{H}-{ }^{1} \mathrm{H}\right.$ COSY, HMQC, NOESY and HMBC) spectra data and comparison with the data of the known compounds nemorosinic acid B [13], adlupulone [19], and garcinenone F [20]. Comparison of the ${ }^{13} \mathrm{C}-\mathrm{NMR}$ data of 1 with those of adlupulone, which was isolated from Humulus lupulus L. [19], revealed that 1 contained two enolic C-atoms at $\delta(C) 170.4(\mathrm{C}(3))$ and $191.9(\mathrm{C}(5))$, one $\mathrm{C}=\mathrm{O}$ group at $\delta(\mathrm{C}) 205.5(\mathrm{C}(1))$, and three quaternary carbons at $\delta(C) 103.3(\mathrm{C}(2)), 109.6(\mathrm{C}(4))$, and $60.9(\mathrm{C}(6))$, which was the same as for adlupulone and garcinenone $\mathrm{F}$. Thus, 1 was characterized as having a cyclohexa-2,4-dien-1-one moiety. Extensive analysis of ${ }^{1} \mathrm{H}$ - and ${ }^{13} \mathrm{C}-\mathrm{NMR}$, together with $\mathrm{HMBC}$ spectra, indicated the presence of a 3-methylbut-2-en-1-yl group $(\delta(\mathrm{H}) 2.53$ (brd, $J=7.3 \mathrm{~Hz}, 2 \mathrm{H}, \mathrm{H}-22), 4.77$ (m, H-23), 1.51 (s, 3H, H-26), and 1.48 (s, 3H, H-25); $\delta(\mathrm{C}) 42.2(\mathrm{C}(22)), 116.8(\mathrm{C}(23)), 135.6(\mathrm{C}(24)), 25.8(\mathrm{C}(26)$, and $17.8(\mathrm{C}(25))$, an oxidized lavandulyl group $(\delta(\mathrm{H}) 2.26$ (brd, 10Hz, H-12a), 2.08 (m, H-12b), 2.14 (m, H-13), 4.51/4.42 (brs, H-15a, 15b), 1.48 (s, 3H, H-16), 2.14 (m, H-17), 6.64-6.68 (m, H-18), and 1.77 (s, 3H, H-21); $\delta(\mathrm{C})$ $40.4(\mathrm{C}(12)), 44.4(\mathrm{C}(13)), 145.7$ (C(14)), $114.1(\mathrm{C}(15)), 17.6$ (C(16)), 33.3 (C(17)), 142.5 (C(18)), 127.5 $(\mathrm{C}(19)), 172.2(\mathrm{C}(20))$, and $12.0(\mathrm{C}(21))$ (Figure 1, Table 1), a 2-methylbutanoyl group $(\delta(\mathrm{H}) 3.53$ (sextet, 1H, H-28), 1.45 (m, H-29a, 1.75 (m, H-29b), 0.93 (t, 7.3 Hz, 3H, H-30), and 1.18 (d, 6.8Hz, 3H, H-31); $\delta(C) 196.5(\mathrm{C}(27)), 40.7(\mathrm{C}(28)), 27.4(\mathrm{C}(29)), 11.9(\mathrm{C}(30))$, and $17.2(\mathrm{C}(31))$, and a 2,3-dioxy3-methylbutyl moiety $(\delta(\mathrm{H})$ 2.87-3.01 (m,H-7a,7b), 4.75-4.83 (m, 1H, H-8), 1.32 (s, 3H, H-10), and 
$1.26(\mathrm{~s}, 3 \mathrm{H}, \mathrm{H}-11)) ; \delta(\mathrm{C}) 26.6(\mathrm{C}(7)), 92.4(\mathrm{C}(8)), 71.8(\mathrm{C}(9)), 24.8(\mathrm{C}(10))$, and $24.6(\mathrm{C}(11))$ (Table 1). The positions of the substituents were deduced by analysis of the HMBC data (Table 1, Figure 1). The HMBC cross-peaks of $\mathrm{CH}_{2}(22)$ and $\mathrm{CH}_{2}(12)$ with $\delta(\mathrm{C}) 205.5(\mathrm{C}(1), 191.9(\mathrm{C}(5)$, and $60.9(\mathrm{C}(6)$, established that a 3-methylbut-2-en-1-yl and lavandulyl group were linked to $\mathrm{C}(6)$. The observed signals on the HMBC spectrum of ${ }^{\mathrm{n}} \mathrm{JHC}_{\mathrm{HC}}$ of $\mathrm{CH}_{2}(7)$ with $\delta(\mathrm{C}) 109.3(\mathrm{C}(4)), 170.4(\mathrm{C}(3)), 92.4(\mathrm{C}(8))$, and 71.8 (C(9)) allowed to located the 2,3-dihydro-2-(1-hydroxyl-1-methylethyl)-furan moiety at $\mathrm{C}(3)$ and $\mathrm{C}(4)$, different from those of garcinenone F [20]. Besides other long range coupling signals, the value 191.9 of $\mathbf{1}$ (with $\mathrm{H}-22$ and $\mathrm{H}-17$ ) allowed to locate the enolic $\mathrm{OH}$ group at $\mathrm{C}(5)$, different of $\mathrm{C}(5)$ in garcinenone $\mathrm{F}$ [20]. The remaining 2-methylbutanoyl group was attached at $\mathrm{C}(2)$ based on the ${ }^{3} J_{\mathrm{HC}}$ of $\mathrm{H}-28$ and $\mathrm{C}(2)$ $\left(\delta_{C} 103.5\right)$ (Table 1$)$. The chemical shifts of $\mathrm{H}_{a}$ and $\mathrm{H}_{b}$ of $\mathrm{C}(7), \mathrm{C}(17)$, and $\mathrm{C}(22)$ were overlapped in the ${ }^{1} \mathrm{H}-\mathrm{NMR}$ (see supplementary material).

Table 1. ${ }^{1} \mathrm{H}(500 \mathrm{MHz})$ and ${ }^{13} \mathrm{C}(125 \mathrm{MHz}) \mathrm{NMR}$ data of $\mathbf{1}$ in $\mathrm{CDCl}_{3}$.

\begin{tabular}{|c|c|c|c|}
\hline Position & $\delta_{H}$ & $\delta \mathbf{C}$ & HMBC $\left({ }^{2,3} J_{\mathrm{H}-\mathrm{C}}\right)$ \\
\hline 1 & - & 205.6 & - \\
\hline 2 & - & 103.5 & - \\
\hline 3 & - & 170.4 & - \\
\hline 4 & - & 109.3 & - \\
\hline 5 & - & 191.9 & - \\
\hline 6 & - & 60.9 & - \\
\hline 7 & $2.87-3.01(\mathrm{~m})$ & 26.6 & C-3; C-4; C-5; C-8; C-9 \\
\hline 8 & $4.75-4.83(\mathrm{~m})$ & 92.4 & C-3; C-4 ;C-10; C-11 \\
\hline 9 & - & 71.8 & - \\
\hline 10 & $1.32(\mathrm{~s})$ & 24.8 & C-8; C-9; C-11 \\
\hline 11 & $1.26(\mathrm{~s})$ & 24.6 & C-8; C-9; C-10 \\
\hline 12 & $2.26(\mathrm{br} \mathrm{d}, 10 \mathrm{~Hz}, \mathrm{H}-12 \mathrm{a}) ; 2.08(\mathrm{~m}, \mathrm{H}-12 \mathrm{~b})^{\mathrm{a}}$ & 40.4 & C-1; C-5; C-6; C-13; C-14; C-17 \\
\hline 13 & $2.14(\mathrm{~m})$ & 44.4 & C-6; C-14; C-15; C-17 \\
\hline 14 & - & 145.7 & - \\
\hline 15 & 4.51 (brs, H-15a); 4.52 (brs, H-15b) ${ }^{a}$ & 114.1 & C-13; C-14; C-16 \\
\hline 16 & $1.48(\mathrm{~s})$ & 17.8 & C-13; C-14; C-15 \\
\hline 17 & $2.14(\mathrm{~m})$ & 33.3 & C-12; C-14; C-18; C-19 \\
\hline 18 & 6.68 (brt, $6.6 \mathrm{~Hz})$ & 142.5 & C-13; C-17; C-19; C-20; C-21 \\
\hline 19 & - & 127.5 & - \\
\hline 20 & - & 172.2 & - \\
\hline 21 & $1.77(\mathrm{~s})$ & 12.0 & $\mathrm{C}-18 ; \mathrm{C}-19 ; \mathrm{C}-20$ \\
\hline 22 & 2.53 (brd, $7.3 \mathrm{~Hz})$ & 42.2 & C-1; C-5; C-6; C-12; C-23; C-24 \\
\hline 23 & $4.75-4.83(\mathrm{~m})$ & 116.8 & C-22; C-25; C-26 \\
\hline 24 & - & 135.6 & - \\
\hline 25 & $1.48(\mathrm{~s})$ & 17.6 & $\mathrm{C}-23 ; \mathrm{C}-24 ; \mathrm{C}-26$ \\
\hline 26 & $1.51(\mathrm{~s})$ & 25.7 & $\mathrm{C}-23 ; \mathrm{C}-24 ; \mathrm{C}-25$ \\
\hline 27 & - & 196.5 & - \\
\hline 28 & 3.53 (sextet, $6.8 \mathrm{~Hz})$ & 40.7 & $\mathrm{C}-2 ; \mathrm{C}-27 ; \mathrm{C}-29 ; \mathrm{C}-30 ; \mathrm{C}-31$ \\
\hline 29 & $1.45-1.50(\mathrm{~m}, \mathrm{H}-29 \mathrm{a}) ; 1.75(\mathrm{~m}, 29 \mathrm{~b})^{\mathrm{a}}$ & 27.4 & $\mathrm{C}-27$; C-28; C-30; C-31 \\
\hline 30 & $0.93(\mathrm{t}, 7.3 \mathrm{~Hz})$ & 11.9 & C-28; C-29 \\
\hline 31 & $1.18(\mathrm{~d}, 6.8 \mathrm{~Hz})$ & 17.2 & $\mathrm{C}-27 ; \mathrm{C}-28 ; \mathrm{C}-29$ \\
\hline
\end{tabular}

${ }^{\mathrm{a}}$ Correlation from ${ }^{1} \mathrm{Hx}{ }^{1} \mathrm{H}-\mathrm{COSY}$ and $\mathrm{HMQC}$ spectra. 


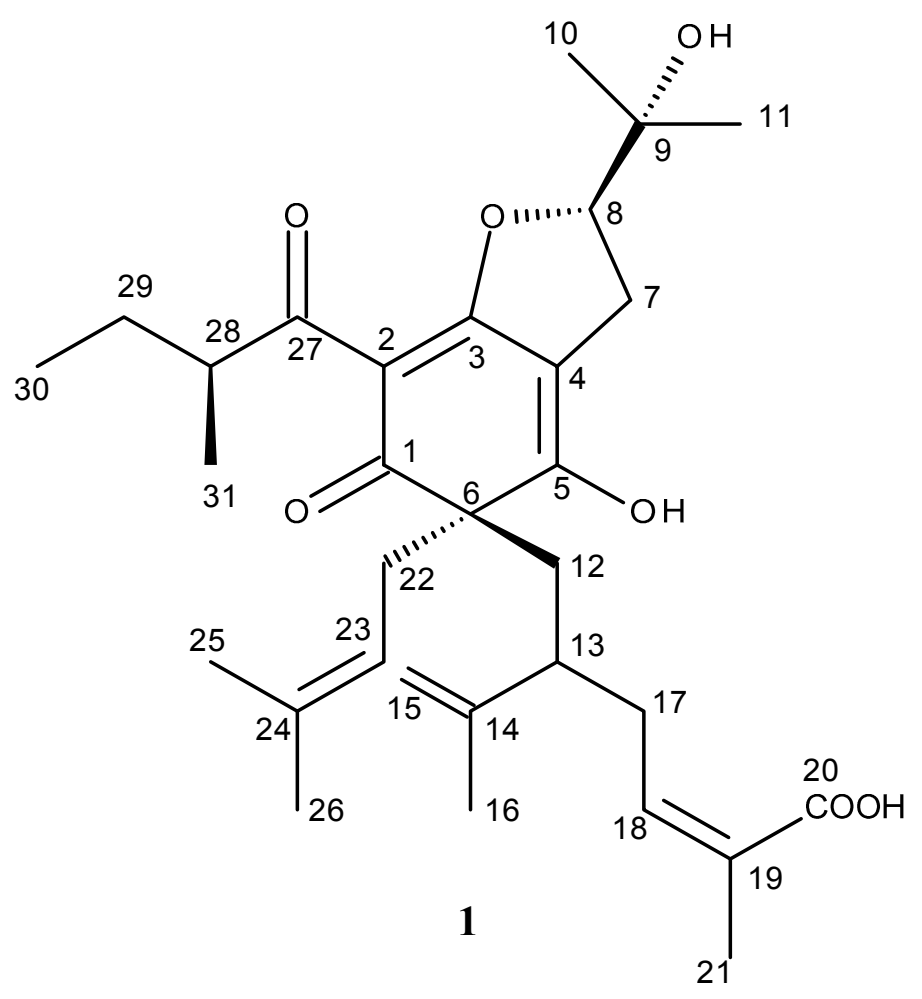

Figure 1. Structure of compound 1.

As described by Monache et al. [13], there is a possibility of epimers at C(28), besides the keto-enolic equilibrium to form tautomeric structures in these kinds of compound. In the case of $\mathbf{1}$, in addition there exists the possibility of epimers at $\mathrm{C}(8)$, and different conformers of the linked groups at $\mathrm{C}(6)$. These structural properties justify the additional signals in the ${ }^{1} \mathrm{H}$ - and ${ }^{13} \mathrm{C}-\mathrm{NMR}$ spectra. Moreover the proposed structure 1 is the major component which provided the chiral properties discussed below. The detailed MS analysis (Figure 2) was used to confirm the structure of $\mathbf{1}$. Various polyisoprenylated phloroglucinol derivatives have being isolated from genus Clusia [13]. Most of them belong to a bicyclononane ring system, as in the case of nemorosonol [12], whereas nemorosic acid, having a cyclohexa-2,4-dien-1-one moiety, is similar to nemorosinic acid B, isolated from Clusia nemorosa [13], lupulone, which occur in Humulus lupulus [9], and garcinenone F, isolated from Garcinia xanthochymus [20]. Lupulone derivatives possess one or more stereogenic centres, but these compounds were racemic $\left([\alpha]_{D}=0\right)$ [9]. However, 1 was optically active $\left([\alpha]_{D}=-5.34^{\circ}\right)$, and the CD curve is presented in Figure 3. Therefore, the configuration of 1 was proposed as $6 S, 8 S, 28 S$ - according to the negative and positive Cotton effect at 340 and $300 \mathrm{~nm}$, respectively (Figure 3), such as (-)-nemorosonol [8] and marmesinin [20], with negative and positive Cotton effect at 250 and $230 \mathrm{~nm}$, containing identical furan system with $S$ configuration [21]. Therefore $\mathbf{1}$ is a new phloroglucinol derivative whose structure was defined as (-)-6S,8S,28S-6-(lavundolyl-6-carboxy)-6-(3methylbut-2-en-1-yl)-2-(2-methylbutanoyl)-[2'-hydroxyiso-propyl-2',3'-dihydrobenzofurane-(2',3':3,4)]5-hydroxycyclohexa-2,4-dienone, named as nemorosic acid. The known compounds were identified by 1Dand 2D-NMR spectroscopic data analysis, and comparison with literature data [14-18]. 


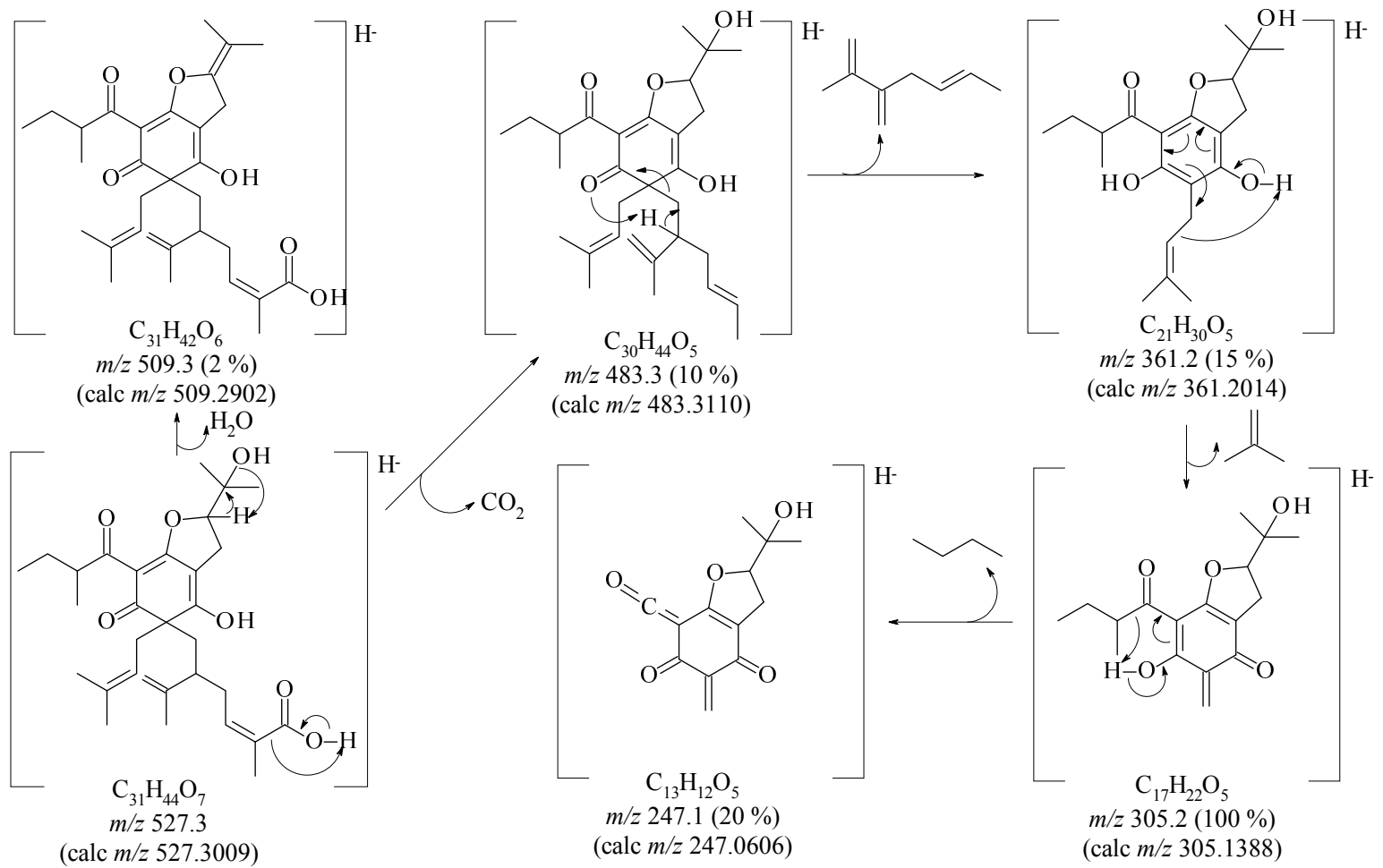

Figure 2. Proposed fragmentation to justify the principal peaks detected in the mass spectrum.

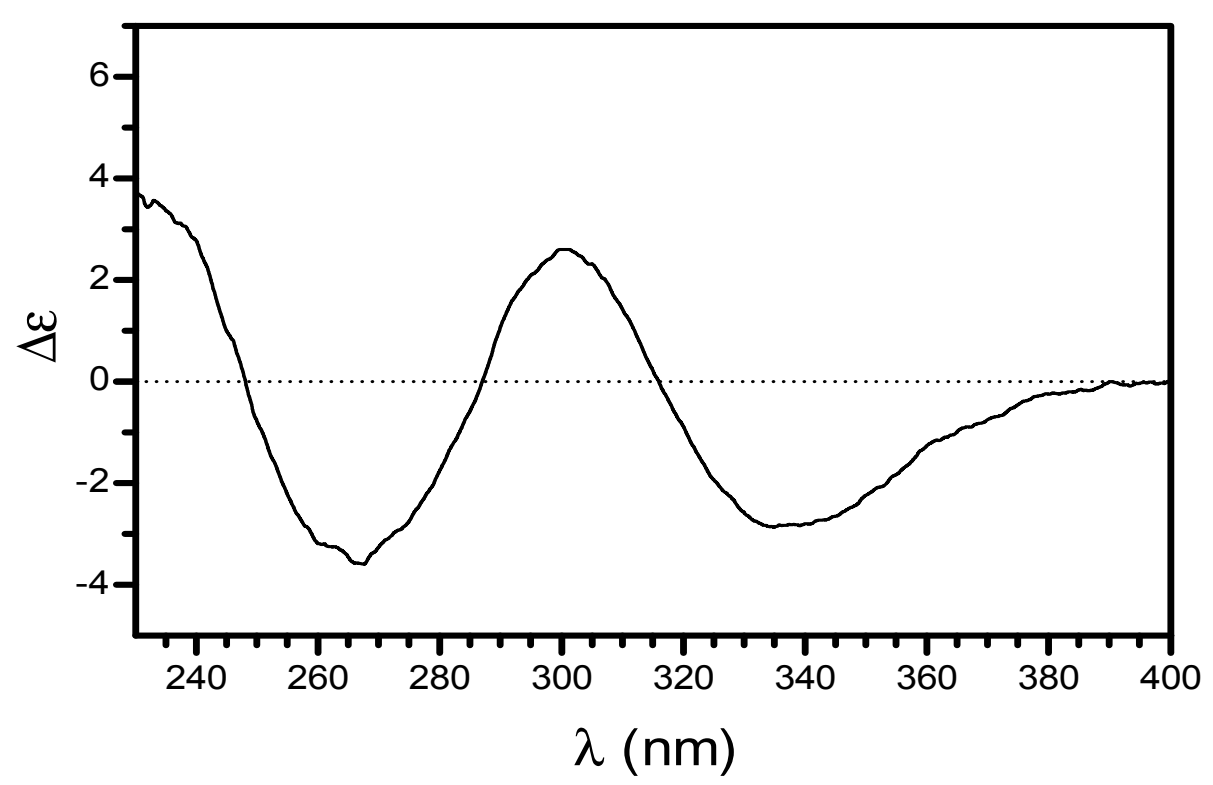

Figure 3. Circular dichroism spectrum of $\mathbf{1}$ in methanol.

\section{Experimental Section}

\subsection{General Procedures}

The melting points were determined with a Mel-temp II apparatus and were uncorrected. IR spectra were obtained with $\mathrm{KBr}$ discs and $\mathrm{NaCl}$ film using a Vertex-70 spectrophotometer (Bruker Corporation, Billerica, MA, USA). UV spectra were obtained on a Shimadzu UV-mini 1240 UV-VIS spectrophotometer (Quioto, Kansai, Japan). ${ }^{1} \mathrm{H}$ - and ${ }^{13} \mathrm{C}-\mathrm{NMR}$ experiments were performed on Bruker Avance III 500 
(Billerica, MA, USA) (500 for ${ }^{1} \mathrm{H}$ and $125 \mathrm{MHz}$ for ${ }^{13} \mathrm{C}$ ) and Bruker AC-400 (400 for ${ }^{1} \mathrm{H}$ and $100 \mathrm{MHz}$ for ${ }^{13} \mathrm{C}$ ) spectrometers using DMSO- $d_{6}$, methanol- $d_{4}$, pyridine- $d_{5}$ or $\mathrm{CDCl}_{3}$ as solvents with TMS as the internal reference. Chemical shifts are in ppm and the $J$ values in Hz. Mass spectra were registered on a microTOFq II-ESI-TOF spectrometer (Bruker Corporation, Billerica, MA, USA) using ESI- in negative mode. Optical rotation was measured with a Jasco P-2000 polarimeter (Easton, MO, USA). The circular dichroism spectrum was realized at DC J-180 Jasco PT4235\190-400 nm. Column chromatography was performed using silica gel (Vetec, Duque de Caxias, RJ, BR and Sigma-Aldrich, St. Louis, MO, USA) $\left(0.05-0.20 \mathrm{~mm}\right.$ ) and Sephadex ${ }^{\mathrm{TM}}$ LH-20 (Sigma-Aldrich, St. Louis, MO, USA). Silica gel F254 G (Vetec) was used for preparative TLC; aluminium-backed Sorbent silica gel plates, w/UV 254, were used for analytical TLC, with visualization under UV (254 and $366 \mathrm{~nm}$ ), with $\mathrm{AlCl}_{3}-\mathrm{EtOH}(1 \%)$, vanillin and iodine vapour.

\subsection{Plant Material}

The fruits of Clusia nemorosa Mey. were collected in the Campus of Universidade Federal Rural de Pernambuco (UFRPE), Recife, Brazil, in January 2012. A voucher (number 51474) is deposited at the herbarium of Vasconcelos Sobrinho (PEUFR), Universidade Federal Rural de Pernambuco.

\subsection{Extraction and Isolation}

The dried fruits $(130.0 \mathrm{~g})$ were extracted with dichloromethane $(2.0 \mathrm{~L})$, followed by extraction with methanol $(2.0 \mathrm{~L})$ at room temperature three times. The two extracts were separately concentrated to give $15.0 \mathrm{~g}$ of $\mathrm{CH}_{2} \mathrm{Cl}_{2}$ extract and $27.0 \mathrm{~g}$ of $\mathrm{MeOH}$ extract. Part of the dichloromethane extract $(11.0 \mathrm{~g})$ was subjected to column chromatography on silica gel with dichloromethane, ethyl acetate (EtOAc) and methanol $(\mathrm{MeOH})$ as eluents to give three fractions (A1-A3). The A2 fraction $(3.0 \mathrm{~g})$ was subjected to repeated silica gel chromatography using hexane- $\mathrm{CH}_{2} \mathrm{Cl}_{2}, \mathrm{CH}_{2} \mathrm{Cl}_{2}-\mathrm{AcOEt}$ and EtOAc-MeOH to furnish the compounds $1(35.0 \mathrm{mg})$ and $\mathbf{5}(65.0 \mathrm{mg})$. The A1 fraction $(5.1 \mathrm{~g})$ was further fractionated through silica gel column chromatography using hexane-EtOAc and EtOAc-MeOH to furnish compounds 2 $(20.0 \mathrm{mg})$ and the mixture of $\mathbf{3}$ and $4(10.0 \mathrm{mg})$. Meanwhile, the dry $\mathrm{MeOH}$ extract $(20.0 \mathrm{~g})$ was suspended in $\mathrm{H}_{2} \mathrm{O}$ and was partitioned with chloroform $(3 \times 200 \mathrm{~mL})$, ethyl acetate $(3 \times 200 \mathrm{~mL})$ and $n$-butanol $(3 \times 200 \mathrm{~mL})$. The EtOAc fraction $(3.5 \mathrm{~g})$ was subjected to Sephadex LH-20 column chromatography and eluted with $\mathrm{MeOH}$ to give five fractions. Fraction 4 was rechromatographed on Sephadex LH-20 and eluted with $\mathrm{MeOH}$ to give $6(5.0 \mathrm{mg})$ and $7(5.0 \mathrm{mg})$. Fraction 5 was rechromatographed over a silica gel column using $\mathrm{CHCl}_{3}-\mathrm{MeOH}(0 \%-100 \%$ methanol) as eluents to give 8 (35.0 mg).

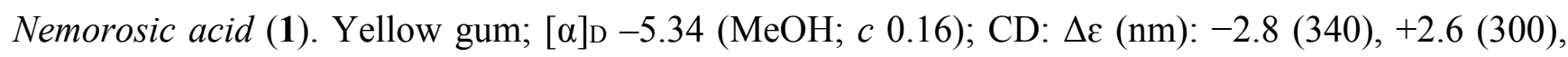
-3.2 (270), +3.7 (230); UV (MeOH) $\lambda_{\max }(\mathrm{nm}): 257$ and 327; IR: $v^{\mathrm{KBr}}\left(\mathrm{cm}^{-1}\right): 3435,1707$, and 1638, besides other signals; ${ }^{1} \mathrm{H}-\mathrm{NMR}\left(500 \mathrm{MHz}, \mathrm{CDCl}_{3}\right)$ and ${ }^{13} \mathrm{C}-\mathrm{NMR}\left(125 \mathrm{MHz}, \mathrm{CDCl}_{3}\right)$, see Table 1; TOF-MS/MS (negative mode) $\mathrm{m} / z$ (rel. int.): 527.3 (70), 509.3 (2), 483.3 (10), 361.2 (15), 305.2 (100) and 247.1 (20), Figure 2. 


\section{Conclusions}

Eight compounds, including the novel compound 1, were isolated from the fruits of C. nemorosa. The discovery of this new compound from the genus Clusia provides more spectroscopic data to characterize the components of its isolates, as well as contribute to the understanding of the taxonomy and evolution of the genus Clusia.

\section{Supplementary Materials}

Supplementary materials can be accessed at: http://www.mdpi.com/1420-3049/20/08/14326/s1.

\section{Acknowledgments}

The authors are grateful to Fundação Carlos Chagas Filho de Amparo a Pesquisa do Estado do Rio de Janeiro (FAPERJ), Fundação de Amparo à Ciência e Tecnologia do Estado de Pernambuco (FACEPE- PRONEM APQ-0741-1.06/14), Coordenação de Aperfeiçoamento de Pessoal de Ensino Superior (CAPES), and to Conselho Nacional de Desenvolvimento Científico e Tecnológico (CNPq) for scholarships and financial support.

\section{Author Contributions}

Rafaela Oliveira Ferreira designed the whole experiment and wrote the manuscript; Tania Maria Sarmento da Silva and Mario Geraldo de Carvalho analysed results and revised the manuscript.

\section{Conflicts of Interest}

The authors declare no conflict of interest.

\section{References}

1. Brittrich, V.; Amaral, M.C.E.; Machado, S.M.F.; Marsaioli, A.J. Floral resin of Tovomitopsis saldanhae (Guttiferae) and 7-epi-nemorosone: Structural revision. Z. Naturforsch. C 2003, 58c, 643-648.

2. Ferreira, R.O.; Carvalho, M.G.; Silva, T.M.S. Ocorrência de biflavonoides em Clusiaceae: Aspectos químicos e farmacológicos. Quim. Nova 2012, 35, 2271-2277.

3. Ferreira, R.O.; Carvalho Junior, A.R.; Silva, T.M.G.; Castro, R.N.; Silva, T.M.S.; Carvalho, M.G. Distribution of metabolites in galled and non-galled leaves of Clusia lanceolata Cambess and antioxidant activity. Braz. J. Pharmacogn. 2014, 24, 617-625.

4. Oliveira, C.M.A.; Porto, A.M.; Bittrich, V.; Vencato, I.; Marsaioli, A.J. Floral resins of Clusia spp: Chemical composition and biological function. Tetrahedron Lett. 1996, 37, 6427-6430.

5. Oliveira, R.F.; Camara, C.A.; Agra, M.F.; Silva, T.M.S. Biflavonoids from the unripe fruits of Clusia paralicola and their antioxidant activity. Nat. Prod. Commun. 2012, 7, 1597-1600.

6. Texeira, J.S.R.; Moreira, L.M.; Guedes, M.L.S.; Cruz, F.G. A new biphenyl from Clusia melchiorii and a new tocotrienol from Clusia obdeltifolia. J. Braz. Chem. Soc. 2006, 17, 812-815.

7. Cruz, F.G.; Texeira, J.S.R. Polyprenylated benzophenones with a tricyclo[4.3.1.1 3 ], undecane skeleton from Clusia obdeltifolia. J. Braz. Chem. Soc. 2004, 15, 504-508. 
8. Oya, A.; Tanaka, N.; Kusama, T.; Kim, S.Y.; Hayashi, S.; Kojoma, M.; Hishida, A.; Kawahara, N.; Sakai, K.; Gonoi, T.; et al. Prenylated benzophenones from Triadenum japonicum. J. Nat. Prod. 2015, 78, 258-264.

9. Zhao, F.; Watanabe, Y.; Nozawa, H.; Daikonaka, A.; Konda, K.; Kitanaka, S. Prenylflavonoids and phloroglucinol derivatives from hops (Humulus lupulus). J. Nat. Prod. 2005, 68, 43-49.

10. Andrade, M.R.; Almeida, E.X.; Conserva, L.M. Alkyl chromone and other compounds from Clusia nemorosa. Phytochemistry 1998, 47, 1431-1433.

11. Farias, J.A.C.; Ferro, J.N.S.; Silva, J.P.; Agra, I.K.R.; Oliveira, F.M.; Candea, A.L.P.; Conte, F.P.; Ferraris, F.K.; Henriques, M.G.M.O.; Conserva, L.M.; et al. Modulation of inflammatory processes by leaves extract from Clusia nemorosa both in vitro and in vivo animal models. Inflammation 2012, $35,764-771$.

12. Cerrini, S.; Lambo, D.; delle Monache, F.; Pinherio, R.M. Nemorosonol, a derivative of tricyclo[4.3.1.0 $0^{3,7}$ decane-7-hydroxy-2,9-dione from Clusia nemorosa. Phytochemistry 1993, 32, 1023-1028.

13. Delle Monache, F.; delle Monache, G.; Gacs-Baitz, E. Two new polyisoprenylated ketones from Clusia nemorosa. Phytochemistry 1991, 30, 703-705.

14. Anjaneyulu. V.; Prasad, K.H.; Rao, G.S. Triterpenoids of the root-bark of Mangifera indica. Indian J. Pharm. Sci. 1982, 44, 85-87.

15. Su-Yeon, K.; Dae-Young, L.; Kyeong-Hwa, S.; Young-Deok, R.; Gye-Won, K.; Dae-Sung, C.; Nam-In, B. Isolation and identification of lipids from the fruits of Acanthopanax sessiliflorus. J. Appl. Biol. Chem. 2012, 55, 103-107.

16. Arora, M.; Kalia, A.N. Isolation and characterization of stigmasterol and $\beta$-sitosterol-D-glycoside from ethanolic extract of the stems of Salvadora pérsica Linn. Int. J. Pharm. Pharm. Sci. 2013, 5, 245-249.

17. Markham, K.R. Techniques of Flavonoid Identification; Academic Press Inc.: London, UK, 1982; pp. 84-86.

18. Hawranik, D.J.; Sorensen, J.L. The isolation of citric acid derivatives from Aspergillus Niger. FEMS Microbiol. Lett. 2010, 306, 122-126.

19. Holtzel, A.; Schlotterbeck, G.; Albert, K.; Bayer, E. Separation and characterisation of hop bitter acids by HPLC- ${ }^{1}$ H NMR coupling. Chromatographia 1996, 2, 499-505.

20. Zhong, F.F.; Chen, Y.; Yang, G.Z. Chemical constituents from bark of Garcinia xantochymus and their 1,1-diphenyl-2-picrylhydrazyl (DPPH) radical-scavenging activities. Helv. Chim. Acta 2008, 91, 1695-1703.

21. Leminich, J.; Havelund, S.; Thastrup, O. Dihydrofurocoumarin glucoside from Angelica archangelica and Angelica silvestris. Phytochemistry 1983, 22, 553-555.

Sample Availability: Samples of all the compounds are available from the authors.

(C) 2015 by the authors; licensee MDPI, Basel, Switzerland. This article is an open access article distributed under the terms and conditions of the Creative Commons Attribution license (http://creativecommons.org/licenses/by/4.0/). 